\title{
Đừng bác bỏ sự giàu có của mình
}

\author{
Vương Quân Hoàng
}

29 June 2007

Chungta.com

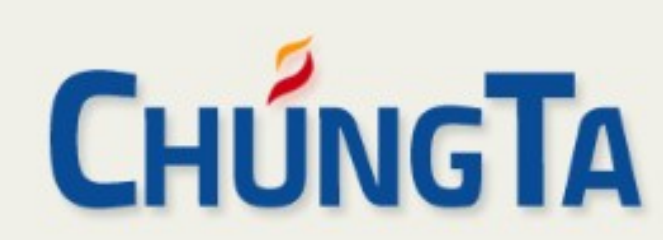

https://www.chungta.com/nd/tu-lieu-tra-

cuu/dung_bac_bo_su_giau_co_cua_minh-8.html 


\section{CHÚNGTA}

\section{Đừng bác bỏ sự giàu có của mình}

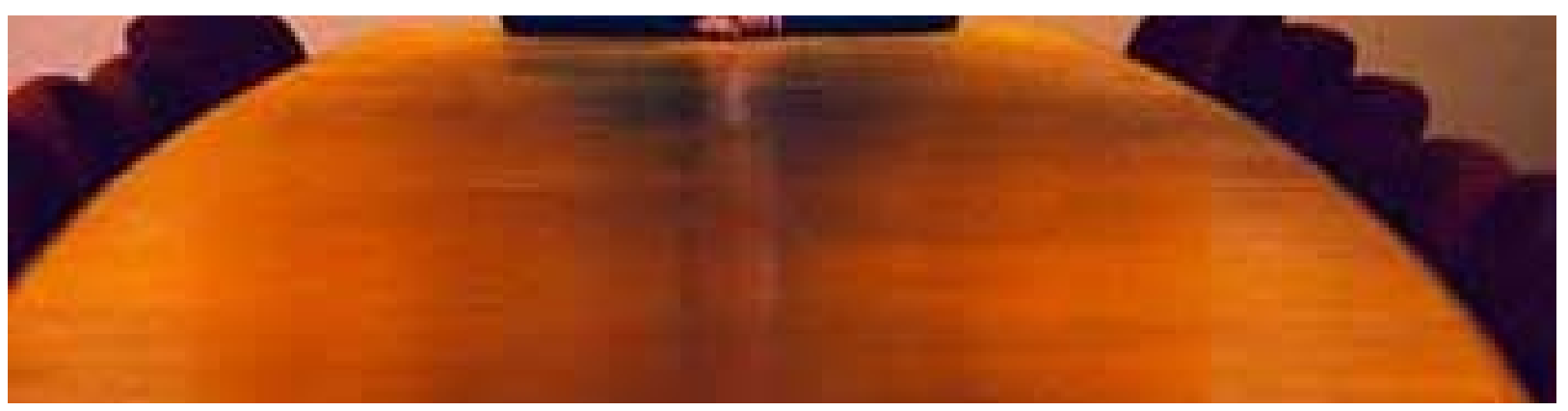

TS Vương Quân Hoàng

07:58 CH @ Thứ Sáu - 29 Tháng Sáu, 2007

Xưa giờ chuyện người giàu ở Việt Nam nói ra khó khăn vô cùng. Hình như ít ai muốn nói. Chuyện cũng lạ là vào năm 2006, khi bỗng báo giới có người muốn thử nghiệm chút khả năng cộng và nhân, phát hiện ra một số "nhà giàu chứng khoán", thì nhiều âm thanh la ó nổi lên. Giới chuyên môn lên tiếng vi phạm cái này cái kia về quyền tự do, rồi nào là thiếu chính xác. Người được vinh danh thì than thở: nào phải thế, đâu được vậy, rồi ai biết nỗi khổ của tôi... Có vẻ như người ta lẩn tránh sự giàu có, không, ý tôi là "cái tiếng" là người giàu có. Điều này rất mâu thuẫn với khát vọng làm giàu thể hiện rõ nét ở doanh nhân, cũng như chuyện kêu gọi nhà đầu tư, tối đa hóa lợi nhuận đang trở thành mục tiêu không chỉ riêng của giới nghiệp chủ.

\section{Tại sao?}

Tại sao việc tìm kiếm những con số giàu có lại nhiều ý nghĩa. Có thể có nhiều cách giải thích khác nhau tới sự quan tâm, nhưng nhìn một cách tích cực, theo chiều hướng vận động xã hội thì có thể lưu ý vài điểm sau.

Trước tiên, các cá nhân giàu có từ hoạt động kinh doanh là người được hưởng kết quả của một quá trình cạnh tranh và nỗ lực kinh doanh. Tài sản của họ thể hiện sự dồi dào tài chính của xã hội được tích lũy sau các thời kỳ kinh doanh đủ dài. Là một phần sự giàu có của xã hội. Là hình ảnh giàu có của quốc gia, lãnh thổ.

Tiếp đến, đối với nhận thức tích cực của xã hội, hình ảnh người giàu là một khát vọng, hướng phấn đấu cho những người đang phấn đấu trong các hệ thống kinh doanh đã tồn tại, cũng như những ai đứng trước thách thức khởi nghiệp.

Thứ ba, việc nắm rỏ cơ cấu phân bố tài sản trong các nhóm dân cư, thuộc vùng lãnh thổ giúp quốc gia như Việt Nam có thể hoạch định các chính sách công bằng xã hội về lâu dài. Thông tin này là bức tranh không thể không biết nếu Chính phủ hướng tới một xã hội công bằng - văn minh.

\section{Một thoáng nhà giàu Mỹ}

Tiến trình giàu có của nước Mỹ thật đáng suy ngẫm. Nước Mỹ là thế lực trỗi dậy về kinh tế ở thế kỷ XVIII, và thực sự trở nên hùng mạnh ở thế kỷ XIX Người ta không làm sao đo đếm được sự giàu mạnh lên của nước Mỹ nếu không biết những người giàu nhất nơi đó có bao nhiêu tài sản. Đứng về mặt khoa học, chúng ta muốn biết sự thật về một số đông thì cũng chỉ cần khảo sát một mầu đủ sức làm đại diện. Đối với sự giàu có của một quốc gia, đó là của cải do những người giàu nhất nắm giữ.

Điều đáng nói là vào ngày độc lập, nước Mỹ chưa hề có một triệu phú nào. Điều này được nhà nghiên cứu KevinPhillips kết luận trong cuốn khảo cứu của ông của cải và dân chủ. Thế nhưng, điều đáng nói là tất cả những người ký tên vào BảnTuyên ngôn độc lập của nước Mỹ đều giàu có và đại diện cho nhiều lĩnh vực sản xuất kinh 


\section{ChúngTa}

nhỏ bé so với các đại gia ChâuÂu. Đó là thương mại, vận tải phục vụ thương mại và công nghiệp phục vụ chiến tranh ở chính ChâuÂu. Cuộc chiến của Napoléon đã đưa họ lên vị trí mới. Nền hàng hải trung lập tương đối của Mỹ là vận hội làm ăn khi các quốc gia giàu có ở ChâuÂu lâm trận với nhau. Những triệu phú đầu tiên ra đời và phải kể tới StephenGirard, vùng Philadelphia, một chủ hãng tàu. Tài sản của ông được ghi nhận vàn năm 1831 khoảng 6,5 triệu USD.

Trước đó người giàu nhất là William Brigham thuộc khoảng 1790 - 1800, ông có tài sản khoảng 3 triệu USD, được xem là triệu phú sớm và giàu nhất. Còn triệu phú đầu tiên của My là EliasHasketDerby vào khoảng năm 1786, doanh nhân ở Salem, bang Massachussetts, chủ hãng tàu và thương gia.

Thời kỳ 1770 - 1900 chính là giai đoạn tích lũy của cải nhanh chóng của Mỹ, và trên thực tế là tích tụ tài sản của các triệu phú Mỹ. Người ta chứng kiến mức tăng tài sản tối đa của cá nhân giàu trong xã hội từ mức 1 triệu lên tới mức 400 triệu trong 130 năm của lịch sử. Thật là bước tiến ngoạn mục. Điều này khiến chúng ta nhớ tới vào những năm giữa thập niên 1980, gia đình nàn có một vài cây vàng được xem là giàu có, thì tới giữa thập niên 1990, số doanh nhân có tài sản một triệu USD ở Việt Nam đã tăng lên con số hàng trăm. Mười năm sau, sự tăng trưởng kinh tế đã đưa số người Việt Nam vào danh mục 100 triệu USD tăng lên đáng kể nhờ cơ chế đánh giá lại tài sản qua thị trường chứng khoán.

\section{Ngẫm lại}

Số triệu phú ở Việt Nam chắc chắn đã tăng lên đáng kể, trong đó có nhiều người nắm giữ hàng trăm triệu USD tài sản qua bất động sản, cổ phiếu, tiền mặt, đồ cổ... Một mặt việc bảo vệ quyền riêng tư cá nhân là cần thiết, nhưng mặt khác khi trở thành người rất giàu có, một tỷ lệ nhỏ cá nhân nắm giữ một tỷ trọng lớn tài sản quốc gia, việc được biết thông tin về tài sản cá nhân cũng có ý nghĩa công bằng với xã hội. Nhưng cuộc điều tra về mức lương trung bình chẳng đã thường xuyên được tiến hành đó sao.

Tâm lý bực bội và lo lắng khi có ai đó ước lượng tài sản của mình hiện đang tồn tại trong số những người giàu tại Việt Nam. Làm sao để sự e ngại này mất đi? Có hai chiều hướng rõ nét. Thứ nhất, định kiến với người giàu cần xóa bỏ bằng cách công nhận công lao và tài năng quản lý, rõ ràng, liên tục và nhất quán. Thế nhưng, chiều hướng thứ hai là chính các doanh nhân với sự dũng cảm gạt bỏ các kiểu làm ăn dối trá, trốn lậu và bất minh. Nói cách khác, việc ngày càng dễ thống kê tài sản lớp người giàu áp đảo tài sản xã hội là một xu hướng khi xã hội tiến tới văn minh kinh doanh. Những thông tin đó cũng chính là một phần của văn minh kinh doanh: minh bạch.

Doanh nhân chân chính trở nên giàu có đồng nghĩa với tài năng kinh doanh được khăng định. Sự giàu có góp phần làm nên thương hiệu cá nhân. Trong quan hệ kinh doanh, hợp tác với một đối tác giàu có sẽ đáng tin cậy hơn, ít trường hợp thất tín hơn. Lý do rất đơn giản, nếu có điều gì bất nhất thì phần lợi tăng thêm chưa hẳn đã có đóng góp đáng kể vào tài sản hiện có của người giàu, nhưng ngược lại, uy tín sẽ bị tổn hại và thiệt hại của việc kinh doanh trong tương lai có thể rất lớn. Doanh nhân không có tiền, không có tài năng, không có thương hiệu sẽ vô cùng khó khăn để tìm được người muốn hợp tác kinh doanh. Như vậy, lợi ích của người giàu đẻ làm ăn rất lớn. Vậy tại sao phải giấu đi sự giàu có của mình. Những người giàu có cũng thường tìm đến với nhau để cùng kinh doanh và trở nên giàu có hơn. Càng ngẫm, lại càng thấy khó mà giải thích vì sao lại phải bác bỏ sự giàu có của chính mình.

\section{Nội dung liên quan}




\section{Chúngta}

- Tư liệu \& Tra cứu

- Con người \& Nhân sinh

- Điều tra xã hội học

Giấy phép MXH: số 63/GXN-TTĐT

Đơn vị chủ quản: Công ty CP Chúng Ta Học

Đơn vị hỗ trợ vận hành: Hanoi Software JSC

Liên hệ: Minh Bùi - minhbui@chungta.com

Website được xây dựng trên nền tảng giải pháp mã nguồn mở VIEApps NGX microservices

๑) 2003 - 2021 ChúngTa.com

$\mathcal{S}$ vieapps.net viebooks.net tyrionguyen.com
- Tác phẩm văn học

- Tác phẩm học thuật

- Tác phẩm học làm người
- Nhân vật Văn hóa

- Nhân vật Hoạt động Xã hội 


\section{TÀl LIẸU THAM KHẢO:}

[1] Nguyễn Văn Hữu, Vương Quân Hoàng. (2007). Các phương pháp toán học trong tài chính. NXB Đại học Quốc gia, Hà Nội.

[2] Vương Quân Hoàng. (2007). Văn minh làm giàu \& Nguồn gốc của cải. NXB Chính trị Quốc gia, Hà Nội. 